\title{
El ciclo de las demandas políticas: una propuesta metodológica aplicada a la contienda por la reforma del marco institucional del agua en Costa Rica
}

\author{
Felipe ALPÍZAR RODRÍGUEZ \\ Universidad de Costa Rica \\ felipealpizar@gmail.com
}

Recibido: 29-11-2013

Aceptado: 28-05-2014

\begin{abstract}
Resumen:
En este artículo se plantea el ciclo de las demandas políticas como una propuesta de modelo teórico y metodológico para estudiar procesos políticos específicos centrándose en las relaciones de poder entre diversos actores y sus demandas. Se postula que la valoración del poder de los actores solo es posible si se consideran los resultados que ese ejercicio del poder produce. Se identifican, por lo tanto, los actores involucrados en un determinado proceso y sus demandas principales durante la contienda. Esto último, a través del análisis puntual de la contienda política más importante ocurrida en el pasado reciente en torno al recurso hídrico en Costa Rica: la lucha por la reforma del marco normativo del agua durante el periodo que se extiende entre 1996 y 2010. La espiral del poder en la contienda por la reforma del marco jurídico del recurso hídrico en dicho periodo consta de cinco ciclos en los que varios actores de la sociedad civil -académicos, empresariales o ecologistas, entre otros, así como los principales partidos políticos- se enfrascaron en extensos debates y luchas políticas para direccionar el sentido de la reforma o impedirla. En virtud de lo anterior, se realizó un análisis de la demanda central de cada actor relevante en la espiral de contienda y una valoración de su incidencia política en función de su nivel de cumplimiento. El concepto de incidencia política es entendido como el mecanismo explicativo del desenlace del proceso; esto es, que la verificación empírica de la incidencia política permite descifrar las relaciones de poder imperantes.
\end{abstract}

Palabras clave: poder, demandas, actores, modelo, Costa Rica, agua 


\title{
The cycle of the political demands: a methodological model applied to the episode of contentious politics over the reform for water's legal framework in Costa Rica
}

\begin{abstract}
This paper proposes a theoretical and methodological model for the analysis of the political process by focusing on the stakeholders, their demands and their power relations. It postulates that power relations can be studied by considering the effects produced by the exercise of power. To do so, it identifies the main stakeholders in a political process and their main demands. The model is applied to a specific episode of contentious politics in Costa Rica: the dispute over the reform for water's legal framework occurred between 1996 and 2010. The so-called power spiral over the reform is composed by five different demands cycles in which many stakeholders, such as NGO's, academic actors, ecologist and corporations, as well as political parties and public institutions debated and fought about the directions of the reform and in some cases tried to veto it. The power relations between them were studied, as said before, by identifying the main demand of each political actor and then evaluating their political incidence by considering the compliance (or not) of each demand at the end of the political process. This paper concludes that this method and in particular the study of the political incidence of the demands of the stakeholders serves as a causal mechanism of the outcome of the process and helps study power relations.
\end{abstract}

Keywords: power, demands, stakeholders, framework, Costa Rica, water

\section{Referencia normalizada}

Alpízar Rodríguez, F.. (2014). "El ciclo de las demandas políticas: una propuesta metodológica aplicada a la contienda por la reforma del marco institucional del agua en Costa Rica”. Política y Sociedad, Vol 51, Núm. 2: 619-640

Sumario: Introducción. 1. Modelo de análisis para el estudio del poder: el ciclo de las demandas políticas. 2. La contienda por la reforma del marco legal del recurso hídrico: aplicación empírica del modelo. 3. Conclusiones. Bibliografía. 


\section{Introducción}

A pesar de que existen relaciones de poder en prácticamente todas las áreas de trabajo de la Ciencia Política, su estudio ha sido elusivo, al punto de que, en cierta medida, dicha problemática sigue siendo una materia pendiente de la disciplina. Numerosos intelectuales han procurado desenmascarar las lógicas del poder presentes en la relaciones sociales actuales o pasadas, y es precisamente a partir de autores como Lukes (2007), Foucault (1981), Mann (1984), Bourdieu (1985) y Castells (2009), entre otros, que este artículo pretende abordar el desafío del estudio del poder a través del análisis de los conflictos relacionados con la reforma al marco normativo del recurso hídrico en Costa Rica.

Para ello se parte de una premisa básica: solo es posible estudiar las relaciones de poder en contextos específicos que permitan determinar los resultados que ese ejercicio del poder produce (Lukes, 2007:113). Tal y como lo señala Castells (2009:551) para ello se debe determinar los procesos y contextos en los que se ejerce el poder.

Frente a ese desafío, se plantea que un modelo teórico y metodológico que se base en el ciclo de las demandas políticas puede ser útil para estudiar procesos políticos específicos centrándose en las relaciones de poder entre diversos actores y sus demandas.

Más allá de la elaboración teórica, este artículo se enfoca en analizar un tema de suma relevancia: la gestión del agua. Así pues, con el fin de demostrar si dicho modelo de gestión funciona en la práctica, se analiza el proceso político ocurrido en Costa Rica entre 1996 y 2010, que estuvo marcado por las luchas de distintos actores alrededor de una eventual reforma integral del marco normativo del recurso hídrico.

Se explican, en primera instancia, los postulados teóricos básicos del modelo, para luego proceder al análisis empírico del proceso antes descrito. Luego se recapitulan los hallazgos teóricos y empíricos más relevantes en la sección de conclusiones.

\section{Modelo de análisis para el estudio del poder: el ciclo de las demandas políticas}

La crisis de los partidos políticos y, en general, los desafíos que enfrentan los mecanismos institucionales de representación de los intereses, son fenómenos comunes en buena parte de los países de la región. Costa Rica no es la excepción, tal como lo señala Hernández: "[...] en las últimas décadas, se ha observado el surgimiento de una mayor cantidad de organizaciones sociales y movimientos que se han convertido en espacios de participación no partidaria, al menos a nivel de dirigentes y cuadros profesionales, así como de temas o problemas específicos." (2009:16). 
Estos fenómenos obligan a ampliar la mirada académica sobre la intermediación de intereses más allá de los partidos políticos. Por lo anterior, el foco del análisis democrático debería ponerse también en el ejercicio del poder de los distintos actores no partidarios y las formas en las que canalizan sus intereses.

En consonancia con el supuesto de partida planteado en la introducción, para identificar cómo ocurre esa intermediación de intereses mediada por las relaciones de poder, es preciso buscar espacios o contextos de debate político que permitan, primero, identificar los intereses de los actores. En este sentido, es importante considerar que el ejercicio del poder, y en particular la dominación, buscan que unos determinados intereses no se conviertan en demandas. De acuerdo con esa perspectiva, el estudio del poder debe tener en cuenta sus tres dimensiones (Lukes, 2007). Así, no resulta suficiente entender el poder como la capacidad de A de determinar el comportamiento de B, sino también como la capacidad de un agente de evitar que surjan los conflictos, de que no se tomen decisiones sobre ciertos temas y se escondan problemas potenciales (segunda dimensión). Adicionalmente, la consideración de una tercera dimensión del poder obliga a poner atención no solo a la toma de decisiones, sino también al control del programa o agenda política, los problemas potenciales, los asuntos sobre los que no se han tomado decisiones y aquellos temas que no se han convertido en conflictos porque algún agente poderoso está interesado en sacarlos del ámbito de la política.

La definición del poder -advierte Lukes- es intrínsecamente polémica, toda vez que su estudio "[...] implica juzgar la importancia de los resultados que los poderosos pueden producir [...] determinar quiénes tienen más poder, y cuánto más poder tienen, es inseparable de valorar la importancia del impacto de su poder, esto es: de su impacto sobre los intereses de los afectados.” (2007: 133) Así, el poder se entiende como las "[...] aptitudes de los agentes para producir efectos importantes, específicamente al promocionar sus intereses y/o afectar los intereses de los otros, sea de manera positiva o negativa.” (Lukes, 2007:70).

Precisamente para atender al enfoque multidimensional del poder, este artículo establece que la demanda política se deriva de la construcción política de un interés. Cuando el ejercicio del poder de un agente impide que los intereses del otro agente se constituyan siquiera en demandas, se estaría en presencia de un ejercicio del poder en la forma de la dominación, que además le impide a ese agente el disfrute de las oportunidades de desarrollo y la satisfacción de sus necesidades básicas (Lukes, 2007; Castells, 2009).

En consonancia con lo anterior, la propuesta de análisis parte del supuesto de que es posible estudiar las demandas políticas siguiendo una especie de ciclo de vida. En otras palabras, la comprensión de la política como una actividad humana dinámica, iterativa y relacional, conlleva no solamente estudiar las demandas en un momento determinado, sino rastrearlas a lo largo del proceso político. Esta idea se extrae del análisis de políticas públicas que, a partir de un asunto que genera el interés público, considera lo que ocurre en cada una de las fases, identificando elementos distintivos para cada una de ellas (Abarca, 2002). No obstante lo anterior, en este caso el énfasis se pone en las posturas de los actores frente a determinados 
temas y no en el diseño de una política para atender el asunto. De nuevo, se trata de mover el foco del lente hacia las demandas de los actores para poder visibilizar procesos que no se canalizan necesariamente por la vía tradicional de los partidos políticos y las políticas públicas y que, por eso mismo, no siempre están a la vista.

Así, el modelo plantea que es posible identificar cuatro fases distintas en el análisis de las demandas:

1. Proceso de construcción/destrucción de las demandas de los actores políticos

En esta fase se estudia la forma en que los intereses se convierten en demandas, o si, por el contrario, son destruidas (o no defendidas políticamente). Cabe recordar que un interés se convierte en demanda cuando es construido políticamente y defendido frente a otros actores y/o instituciones. Esto supone que las situaciones cotidianas, necesidades, preferencias y agravios son problematizados y elaborados intersubjetivamente hasta llegar al convencimiento de que se requiere defenderlos por medio de la acción política. Es claro que este paso lleva implícito determinados recursos de poder que les permitan a los agentes realizar ese proceso de problematización y, concretamente, defender en la arena simbólica su interpretación frente a otros actores, sean internos o externos, que quieran imponer un curso de acción distinto.

2. Articulación y desarticulación de las demandas de los actores políticos Una vez que los actores han construido sus demandas, estas deben pasar por el espacio público-político, donde confluyen distintos problemas que requieren ser resueltos por el sistema político. Los actores políticos colocan sus demandas en un espacio público donde colisionan o se apoyan en las demandas de los otros actores políticos que también pretenden que las instituciones del sistema político resuelven sus peticiones. Castells define el espacio público como "[...] el espacio de la interacción social y significativa donde las ideas y los valores se forman, se transmiten, se respaldan y combaten" (2009:394). En razón de lo anterior, se habla de la articulación y desarticulación de las demandas políticas, proceso que ya no depende únicamente de los actores en sí mismos, sino de las complejas interrelaciones que ocurren entre los distintos actores, los medios de comunicación, la opinión pública, los partidos políticos y las instituciones políticas. La lucha simbólica por la primacía en la opinión y la agenda pública está mediada por procesos de establecimiento de la agenda (setting), la priorización (priming) o el enmarcado (framing). El espacio público se convierte entonces en el lugar de la deliberación y sirve, por lo tanto, como mecanismo de discusión y selección de las preferencias colectivas.

3. Procesamiento institucional de las demandas

Las demandas planteadas y articuladas por los actores políticos pretenden ser incorporadas dentro del sistema político por las instituciones del Estado. Así, el procesamiento institucional de las demandas se refiere a todas aquellas acciones u omisiones de las autoridades gubernamentales en relación con las 
demandas planteadas por los actores políticos. Dichas demandas, que forman parte de la agenda pública, no se componen únicamente de aquellas perseguidas por los grupos de presión, los movimientos sociales y las organizaciones comunales, sino que engloban también temas planteados por los partidos políticos, los medios de comunicación y, por supuesto, las mismas autoridades del sistema político. El estudio de las demandas permite situar el debate en el plano empírico para indagar todas las variantes que puedan ocurrir en los intercambios entre las instituciones y los actores políticos. En este sentido, resulta interesante considerar si existe una inclusión simétrica o asimétrica en la agregación de intereses de los actores en la discusión y decisión de los asuntos públicos (Prats, 2004; Powell, 2007).

4. Interpretación simbólica del desenlace

La cuarta fase pretende dar cuenta de la forma en que los actores políticos reciben, entienden e interpretan el procesamiento institucional de sus demandas. Se debe recordar que ya para este momento la demanda ha superado distintas etapas y en cada una de ellas los actores han ajustado sus expectativas de acuerdo con sus marcos cognitivos y los procesos simbólicos que enmarcan su accionar. Es posible que el procesamiento institucional de la demanda del actor haya sido más bien la no incorporación de la reivindicación como un asunto público; es decir, el rechazo de la demanda. En este caso, los actores tienen que interpretar ese desenlace y decidir con sus recursos simbólicos y políticos disponibles si se desea reconstruir la demanda en términos distintos, si se desea continuar la lucha por otros mecanismos, o si el tema se da por agotado y se abandona la contienda. De igual manera, si existe un procesamiento institucional de sus demandas positivo -es decir, que la demanda ha sido incluida aunque sea de forma asimétrica- los actores deben interpretar si el resultado de sus luchas cumple con sus expectativas o no. En este caso, podrían reiniciar su lucha o darla por terminada. Esta fase representa de alguna manera el final del ciclo, pero se trata de un final abierto, que no supone un cierre. El ciclo es solo un giro de una espiral que puede continuar tantas veces como alguno de los actores -uno, varios o todos- lo considere necesario. Por supuesto que en esta espiral las relaciones de poder entre los actores son determinantes, incluso para decidir si el asunto debe continuar discutiéndose o no y en qué términos. Por ello, justamente, se le denomina la espiral del poder.

La división analítica del proceso en cuatro fases pretende facilitar la identificación de los actores y sus demandas en cada una de ellas. Por lo anterior se ha denominado el proceso como el ciclo de las demandas políticas, aunque no se trata de un círculo que se cierra en sí mismo y, por ende, no vuelve a sus inicios de forma inalterada, ni supone un cierre. La práctica política cambia irremediablemente a sus actores y nunca es posible volver al estado de cosas inicial. De acuerdo con este enfoque, el ciclo es simplemente una parte -un giro- de una espiral que puede 
continuar o no según el asunto político en cuestión tenga vigencia desde la perspectiva de los actores involucrados. Por ello, es posible plasmar gráficamente el concepto de la espiral del poder, dado que este hace referencia a las dinámicas continuadas de relaciones de poder en torno al conflicto sobre un determinado asunto y las respectivas demandas de los actores en distintos ciclos.

En la figura 1.1 se puede observar gráficamente la idea del ciclo y la espiral del poder. Cabe destacar que esta representación gráfica puede ser muy útil para representar los procesos políticos; incluso, permite imaginar una representación de la realidad política de un país en un momento determinado como una compleja combinación de espirales de poder -tantas como temas existan en la agenda pública- que se solapan, se influyen, se anulan o se potencian.

Figura 1: El ciclo de las demandas políticas y la espiral del poder

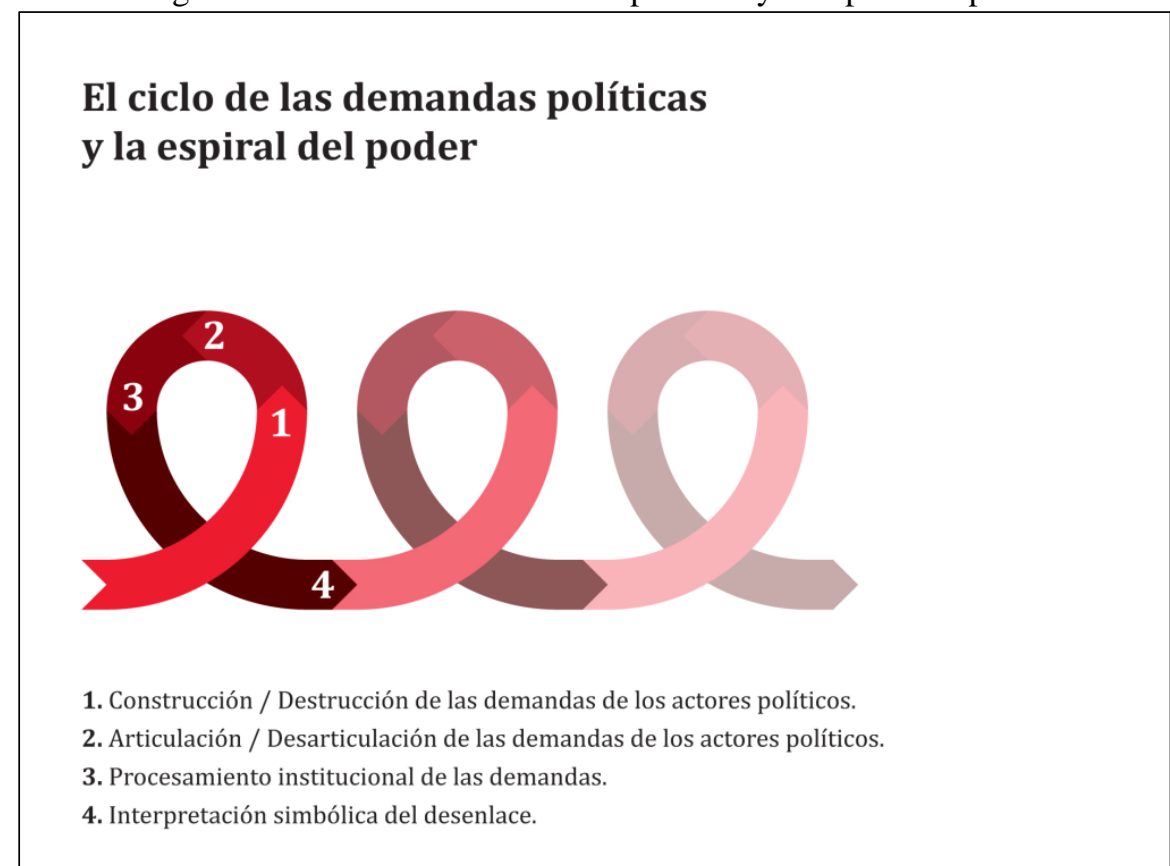

Fuente: Elaboración propia.

La idea del ciclo y sus fases pretende facilitar la comprensión del proceso político de participación de los actores y la intermediación de sus intereses. Es importante señalar que, aunado a ello, el modelo pretende utilizar el concepto de incidencia política como una medida de los efectos de la participación, pues como lo señala Castells (2009:394) "[...] sólo sabemos si las acciones colectivas fueron realmente sujetos del cambio social por sus repercusiones".

El concepto de incidencia política en Centroamérica está profundamente ligado a la acción política de las organizaciones de la sociedad civil. Una vez que las 
ilusiones de cambio social fueron derrotadas después de las sangrientas guerras en la región, los actores sociales tuvieron que adaptar sus reivindicaciones a las nuevas corrientes de la incipiente democratización. Así, la incidencia política se entendió como la vía institucionalizada para el cambio político hacia las anheladas reivindicaciones sociales de inclusión y bienestar (De la Ossa, 2002; WOLA, 2005). A partir de la reelaboración del concepto por parte de Blanco (2006) y Alpízar (2007) se puede considerar la incidencia política desde un punto de vista simbólico, discursivo y comunicativo, en el sentido de que implicaría un impacto en la gestión de los asuntos comunes a la sociedad. Con base en lo anterior, es posible redefinir el concepto de incidencia política como la capacidad de los grupos organizados para actuar frente a las entidades públicas e incorporar sus demandas en el proceso de decisión gubernamental. Esta definición precisa la noción más general de influencia política, más relacionada con el poder abstracto o potencial de los actores políticos (Alpízar, 2007). Así, la incidencia política es una forma de participación política con cinco elementos fundamentales:

1. Se trata de una actividad no electoral, es decir, se produce fuera del marco de los procesos electorales;

2. Es ejercida por grupos sociales organizados, lo cual excluye el accionar de los ciudadanos no organizados en grupos (Tilly y Tarrow, 2007);

3. El estudio de los actores políticos que realizan incidencia se realiza a partir de cuatro dimensiones teóricas para el análisis, lo cual supone identificar su estructura organizativa, sus marcos cognitivos, la estructura de oportunidades de su contexto y sus efectos políticos;

4. El análisis de la incidencia se realiza siguiendo el ciclo de las demandas políticas;

5. La incidencia política se puede verificar empíricamente en la medida en que se determine el éxito de los grupos en hacer llegar sus demandas hasta el final del ciclo e incorporar plenamente sus reivindicaciones en las decisiones públicas.

A partir de esto se puede establecer una especie de escala de incidencia política, que va aumentando su valor conforme las demandas logran transitar de una fase a la otra del ciclo de las demandas políticas.

El concepto de incidencia política es entonces el hilo conductor de este enfoque, pues permite seguir la demanda en todo su proceso y medir empíricamente el nivel de eficacia de la participación política. Así pues, si un actor o un grupo de actores monopolizan la participación política e imponen sus demandas, de forma tal que impiden a los demás la satisfacción de sus necesidades más elementales, por ejemplo en torno al agua, entonces se habla de dominación y un ejercicio no democrático del poder (Lukes, 2007).

La propuesta de modelo parte además de la lógica del análisis de coyuntura, que ha sido ampliamente trabajada en la región centroamericana por diversos académicos (Abarca et.al., 2012). En términos metodológicos, se parte de un hecho 
detonante para marcar el inicio del ciclo y se registran los hechos relevantes del periodo de análisis hasta construir una línea de tiempo. En cada ciclo se identifican los actores involucrados y sus demandas principales. Esto permite, además, conocer los temas centrales de la contienda política (Tilly y Tarrow, 2007) y las posiciones de los actores respecto de ella. Las técnicas de investigación que se pueden utilizar en este análisis dependen en buena medida de la naturaleza de la contienda, pero la entrevista, la revisión documental (actas legislativas, minutas de reuniones, cartas, comunicados de prensa), la observación y el análisis de contexto son herramientas privilegiadas para la recolección de la información (Abarca et.al., 2012).

El modelo ha sido aplicado con éxito en varias oportunidades, aunque claramente se trata de una propuesta en construcción que requiere ajustes según se avance en su uso y de acuerdo con las particularidades de cada caso. A continuación se presenta una de las aplicaciones realizada.

\section{La contienda por la reforma del marco legal del recurso hídrico: aplicación empírica del modelo. ${ }^{1}$}

En una investigación de mayor alcance sobre esta materia (Alpízar, 2013), se encontró una tendencia histórica que relaciona las transformaciones profundas en el modelo de desarrollo y forma de Estado con cambios en el marco normativo del recurso hídrico. Así, cada vez que permutaron los equilibrios de poder, los actores dominantes intentaron adecuar la gestión del agua a sus intereses. Esa tendencia se rompe a partir de 1982. En ese año ocurren en Costa Rica importantes cambios societales, que, sin embargo, no fueron acompañados por una reforma integral del marco normativo del recurso hídrico. En los últimos diez años, los principales actores del sector, tanto de la sociedad civil como de las instituciones públicas, se han enfrascado en un largo proceso de debate, consulta y discusión de proyectos de ley tendientes a concretar esa reforma.

En las décadas de 1980 y 1990 se dieron algunos intentos por reformar el marco legal del recurso hídrico y se empieza a discutir cada vez más la necesidad de la reforma en esa materia. Ya para noviembre de 2001, dichos esfuerzos se traducirían en tres proyectos de ley distintos presentados ante la Asamblea Legislativa de Costa Rica por representantes de tres partidos políticos. A partir de entonces inicia un largo periodo de discusión marcado por la polémica, el cual, hasta el día de hoy, no se ha resuelto completamente. Para efectos de la delimitación temporal se ha decidido concentrar el estudio en el periodo comprendido entre los años 1996 y 2010. Cabe indicar que aunque se toman en cuenta algunos antecedentes anteriores a 1996, esa fecha se toma como punto de partida para el análisis, que se extiende

${ }^{1}$ En este artículo se presenta una versión muy resumida del capítulo 6 de la tesis doctoral, en el cual estudio este fenómeno con mayor profundidad (Alpízar, 2013). 
hasta noviembre de 2010, es decir, hasta la presentación del último proyecto de ley relacionado con el recurso hídrico. Es preciso indicar que durante el 2011 y 2012 el proceso ha seguido su curso, sin embargo, por razones metodológicas y de análisis, este periodo más reciente no será analizado en este artículo.

El primer ciclo de contienda inicia en 1996 con el convencimiento de diversos actores respecto a la necesidad de la reforma. A partir de la Conferencia Internacional sobre el Agua y el Medio Ambiente y la Declaración de Dublín toma fuerza el enfoque de la Gestión Integrada de los Recursos Hídricos. En Costa Rica, 1996 marca la constitución de una incipiente comunidad epistémica del agua (Haas, 1992), que, frente a graves episodios de contaminación y un vacío legal en materia de concesiones de fuerzas hidráulicas, planteó la necesidad de una reforma integral del marco legal. Esta primera fase de la construcción de las demandas derivó en la presentación de tres proyectos de ley en noviembre del 2001, que fueron acogidos para estudio y discusión en la Comisión de Ambiente de la Asamblea Legislativa. En este escenario legislativo ocurrió el debate y la confrontación de posiciones que se ubica en la fase de articulación y desarticulación de las demandas, donde se identificaron actores institucionales como el Ministerio de Ambiente y Energía, el Ministerio de Agricultura y Ganadería, así como otros actores de la sociedad civil como la Federación Costarricense para la Conservación de la Naturaleza. La fase de procesamiento institucional de las demandas se puede ubicar en noviembre de 2002, cuando la Comisión Legislativa de Ambiente decide integrar los tres proyectos en uno solo. La tabla 1 recoge la cronología del primer ciclo según los hechos relevantes. Como se explicó antes, la fase de interpretación simbólica del desenlace se traslapa con el siguiente ciclo y se analiza más adelante.

Tabla 1: Cronología del primer ciclo de la contienda por la reforma del marco legal del recurso hídrico, Costa Rica (1996-2002)

\begin{tabular}{|c|c|}
\hline $\begin{array}{c}\text { Hecho relevante } \\
\end{array}$ & Fecha \\
\hline \multicolumn{2}{|l|}{ Fase de construcción/ destrucción de demandas } \\
\hline $\begin{array}{l}\text { La Ley de Autoridad Reguladora de los Servicios Públicos crea un } \\
\text { vacío legal en explotación privada de fuerzas hidráulicas. }\end{array}$ & 1996 \\
\hline En el proceso de concertación nacional se discute el tema hídrico. & 1998 \\
\hline $\begin{array}{l}\text { Episodios de contaminación del agua potable en la Gran Área } \\
\text { Metropolitana afectan a cerca de } 150000 \text {. }\end{array}$ & 2001 \\
\hline El Ministerio de Ambiente y Energía (MINAE) presenta a la & $\begin{array}{l}27 \text { de noviembre } \\
\text { de } 2001\end{array}$ \\
\hline $\begin{array}{l}\text { El diputado Ovidio Pacheco (Partido Unidad Social Cristiana) } \\
\text { presenta el proyecto } 14.594 \text { elaborado por la Defensoría de los } \\
\text { Habitantes (DH). }\end{array}$ & $\begin{array}{l}29 \text { de noviembre } \\
\text { de } 2001\end{array}$ \\
\hline $\begin{array}{l}\text { El diputado José Merino del Río (Partido Fuerza Democrática) } \\
\text { presenta el proyecto 14.598 Ley Marco del Sector Hidrobiológico. }\end{array}$ & $\begin{array}{l}30 \text { de noviembre } \\
\text { de } 2001\end{array}$ \\
\hline \multicolumn{2}{|l|}{ Fase de articulación/desarticulación de las demandas } \\
\hline $\begin{array}{l}\text { La Comisión de Ambiente inicia el trámite del proyecto } 14.585 \text {, } \\
14.594 \text { (Se realizan consultas a sectores). }\end{array}$ & $\begin{array}{l}13 \text { de febrero de } \\
2002\end{array}$ \\
\hline
\end{tabular}




\begin{tabular}{ll}
\hline \multicolumn{1}{c}{ Hecho relevante } & Fecha \\
\hline La Comisión de Ambiente inicia el trámite del proyecto 14.598 & 7 de marzo de \\
(Se realizan consultas a sectores). & 2002 \\
Foro Nacional del Agua organizado por Global Water Partnership & 24 de Abril de \\
y la Asamblea Legislativa. Se crea el Grupo Técnico del Agua & 2002 \\
(MINAE, DH, GWP, Fundación para el Desarrollo Urbano & \\
FUDEU, Centro de Derecho Ambiental y de los Recursos & \\
Naturales CEDARENA. & \\
Se discute la posibilidad de integrar los tres textos a partir del & 25 de Abril de \\
texto del proyecto 14.585. & 2002 \\
Fin de la administración de Miguel Ángel Rodríguez (1998-2002) & 8 de mayo de \\
e inicio de la administración de Abel Pacheco (2002-2006). & 2002 \\
Varios diputados presentan una reforma constitucional, proyecto & 17 de mayo de \\
14.757, para declarar el agua como un bien de dominio público, & 2002 \\
patrimonio del Estado, en el artículo 121, inciso 14 de la & \\
Constitución & \\
\hline
\end{tabular}

Fase de Procesamiento Institucional de las demandas

La Subcomisión que integra los 3 textos, presenta su informe con 11 de noviembre texto sustitutivo 1. Dictamen negativo unánime a los proyectos de 2002 14.594 y 14.598 , ambos se archivan.

Fuente: Elaboración propia a partir de: Expedientes legislativos A-13.061 Tomos 1 a 3, A-11.080, A-11.079. Entrevistas a actores y consultas al sitio oficial de la Asamblea Legislativa, consultado en abril y mayo de 2012:

http://www.asamblea.go.cr/Centro_de_informacion/Consultas_SIL/default.aspx

El segundo ciclo de contienda política abarca el proceso de consulta y la búsqueda de consensos en torno al proyecto; tiene lugar entre los años 2002 y 2003. En la fase de interpretación simbólica del desenlace y la construcción de las demandas, los actores se vieron obligados a estudiar el proyecto de ley sintetizado por la Comisión (proyecto 14.585) y se propuso la creación de un Grupo Técnico del Agua que apoyaba la labor de la Comisión desde las posiciones cercanas a la comunidad epistémica del agua (universidades, organizaciones ecologistas y de la sociedad civil). Se organizaron talleres de consulta del proyecto de la Ley para que otros actores conocieran su contenido y tomaran posición al respecto; además, la Comisión recibió cartas y comparecencias de varias municipalidades del país, instituciones públicas, organizaciones gremiales y empresariales. De nuevo el escenario legislativo sirvió para que los actores articularan sus posiciones y demandas. Así, después de esa fase, en noviembre de 2003, la Comisión Legislativa de Ambiente dictaminó un nuevo proyecto legislativo (14.585-B) 
Tabla 2: Cronología del segundo ciclo de la contienda por la reforma del marco legal del recurso hídrico, Costa Rica (2002-2003)

\begin{tabular}{|c|c|}
\hline Hecho relevante & Fecha \\
\hline \multicolumn{2}{|l|}{ Fase de construcción/ destrucción de demandas } \\
\hline $\begin{array}{l}\text { Se inicia un nuevo proceso de consulta del proyecto } 14.585- \\
\text { A con los actores interesados, tanto instituciones públicas } \\
\text { como privadas, vía cartas, audiencias y talleres de consulta. }\end{array}$ & 11 de noviembre de 2002 \\
\hline Taller de consulta del proyecto 14.585-A en San Carlos & 21 de febrero de 2003 \\
\hline Taller de consulta del proyecto 14.585-A en Quepos & 28 de febrero de 2003 \\
\hline Taller de consulta del proyecto 14.585-A en Limón & 7 de marzo de 2003 \\
\hline Taller de consulta del proyecto 14.585-A en Golfito & 4 de abril de 2003 \\
\hline Taller de consulta del proyecto 14.585-A en Liberia & 25 de abril de 2003 \\
\hline Taller de consulta del proyecto 14.585-A en Palmar Sur & 8 de mayo de 2003 \\
\hline Taller Técnico del Agua en San José & 2-3 de setiembre de 2003 \\
\hline \multicolumn{2}{|l|}{ Fase de articulación/desarticulación de las demandas } \\
\hline $\begin{array}{l}\text { El Grupo Técnico del Agua presenta a la Comisión de } \\
\text { Ambiente una propuesta de texto de ley. }\end{array}$ & 23 de octubre de 2003 \\
\hline Diversos actores presentan sus posiciones ante la Comisión & 2003 \\
\hline \multicolumn{2}{|l|}{ Fase de Procesamiento Institucional de las demandas } \\
\hline $\begin{array}{l}\text { La Subcomisión presenta su informe con la recomendación de } \\
\text { un nuevo texto sustitutivo. Se aprueba el nuevo texto 14.585- } \\
\text { B. }\end{array}$ & 26 de noviembre de 2003 \\
\hline
\end{tabular}

Fuente: Elaboración propia a partir de: Expedientes legislativos A-13.061; Entrevistas a actores; Grupo Técnico del Agua (2004).

La aprobación del nuevo texto de ley propuesto obliga a los actores a reinterpretar nuevamente su posición a la luz de este desenlace. Este hecho marca el inicio del tercer ciclo de contienda que se analiza a continuación. La tabla 2 resume los principales hechos del segundo ciclo de contienda.

El tercer ciclo de contienda se caracteriza por la división institucional y el disenso social, pues una vez aprobado el texto sustitutivo 2, 14.585-B, como dictamen de la Comisión Permanente Especial de Ambiente, se inició la discusión del texto. De inmediato surgieron fuertes polémicas alrededor de la inclusión del tema de regulación de la generación privada de energía y de la reorganización del sector que proponía el proyecto. La fase de articulación de las demandas ocurrió en el escenario legislativo entre noviembre de 2003 y 2004 mediante audiencias a algunos actores y la presentación de cartas y comunicados de prensa de diversos actores. Finalmente, la Comisión emitió un tercer texto sustitutivo (procesamiento institucional de las demandas) en noviembre de 2004, y los actores se vieron obligados de nuevo a reinterpretar este desenlace.

El cuarto ciclo de contienda es de alguna manera el que sintetiza las diversas dimensiones de la disputa por el marco legal. En este caso el ciclo abarca del 2004 al 2005 y culmina con la aprobación del proyecto de ley en la Comisión Permanente 
Especial de Ambiente. El avance hasta ese punto hizo que los diversos actores agudizaran sus posiciones respecto a los cuatro elementos centrales en disputa en este proyecto de ley:

1. La creación de un marco institucional y los principios para asegurar una gestión integrada del recurso hídrico (Ministerio de Ambiente y Energía MINAE, Grupo Técnico del Agua GTA, comunidad epistémica del agua, parte del Poder Ejecutivo y Partido Unidad Social Cristiana PUSC);

2. La regulación de las concesiones de aprovechamiento de fuerzas hidráulicas para generación privada de energía (Asociación Costarricense de Productores Privados de Energía ACOPE, Partido Movimiento Libertario PML vs. Federación Costarricense de Conservación de la Naturaleza FECON y Partido Acción Ciudadana PAC);

3. El equilibrio entre conservación y desarrollo económico (Cámara Nacional de la Agricultura y Agroindustria CNAA, Cámara Costarricense de la Industria Alimentaria CACIA, Cámara de Industrias de Costa Rica CICR, Partido Liberación Nacional PLN, parte del Poder Ejecutivo y PUSC);

4. Los cambios legales que afectarían a instituciones públicas como el Instituto Costarricense de Electricidad ICE, Servicio Nacional de Riego y Avenamiento SENARA e Instituto Costarricense de Acueductos y Alcantarillados ICAA (Poder Ejecutivo dividido-PUSC).

En el proceso de articulación de las demandas, es interesante destacar que la Comisión Legislativa llamó a comparecer a los principales actores interesados en la materia de la regulación de las fuerzas hidráulicas y excluyó a los actores interesados en otros temas. Lo anterior es una muestra de cómo no se cumplió el criterio de inclusión simétrica de los actores. Finalmente, el 14 de abril de 2005, se da el procesamiento institucional de las demandas cuando la Comisión de Ambiente aprueba el dictamen afirmativo por unanimidad del proyecto 14.585-C. Esto cierra el espacio institucional de la Comisión Legislativa como escenario de la incidencia política y los actores deben reinterpretar simbólicamente el desenlace y buscar nuevas posibilidades de intermediación.

El quinto y último ciclo de contienda por la reforma del marco legal en Costa Rica es testigo de la lenta agonía del proyecto de ley 14.585 (2005-2010). La principal razón de esto es que el proyecto de ley encontró una fuerte oposición de actores poderosos, sobre todo aquellos ligados a sectores productivos, que impidieron que el proyecto de ley se discutiese en la corriente legislativa del Plenario costarricense.

La tabla 3 resume la cronología del quinto ciclo de contienda. En este caso particular, el procesamiento institucional de las demandas ocurre de forma separada, pues por un lado se satisface el interés de los sectores relacionados con la producción privada de energía hidroeléctrica por medio de la aprobación del proyecto de Ley 16.949 (Ley 8.723), y por otro lado se evita la discusión del proyecto de ley 14.585 . 
Tabla 3: Cronología del quinto ciclo de la contienda por la reforma del marco legal del recurso hídrico, Costa Rica (2005-2010).

\section{Hecho relevante}

Fecha

Debate en Plenario, se devuelve el proyecto 14.585 a Comisión 9 de agosto de para conocer enmiendas. 2005

Fin de la Administración Pacheco de la Espriella e inicio de la 8 de mayo de Administración Arias Sánchez. 2006

La Comisión de Ambiente discute y desecha las 167 mociones presentadas al proyecto 14.585 .

22 de junio de

El Plenario conoce el informe de la Comisión de Ambiente sobre 28 de agosto de el proyecto 14.585; se presentan 325 mociones adicionales y pasa 2007 de nuevo a Comisión.

La Comisión de Ambiente conoce y desecha las 325 mociones 20 de setiembre presentadas al proyecto 14.585 . de 2007

Se presenta el proyecto 16.897 para incorporar el derecho humano $30 \quad$ de de acceso al agua a la Constitución (arts.50 y 121). noviembre de 2007

Se presenta el proyecto 16.949 Ley Marco de Concesión para el 19 de febrero de aprovechamiento de las fuerzas hidráulicas para la generación 2008 hidroeléctrica.

Creación de la Alianza Nacional para la Defensa del Agua Junio de 2008 (ANDA).

El proyecto 16.949 ingresa a la Comisión de Asuntos 7 al 28 de Agropecuarios, se discute y se dictamina. $\quad$ octubre de 2008

El proyecto 16.949 recibe mociones vía 137 y es conocido en Noviembre de plenario en cuatro ocasiones. 2008 a febrero de 2009

\begin{tabular}{|c|c|}
\hline Primer y segundo debate afirmativo del proyecto 16.949 . & \\
\hline $\begin{array}{l}\text { La Asamblea Legislativa emite la Ley } \mathrm{N}^{\circ} 8723 \text { Marco de } \\
\text { Concesión para el aprovechamiento de las fuerzas hidráulicas para } \\
\text { la generación hidroeléctrica (Proyecto 16.949). }\end{array}$ & $\begin{array}{l}23 \text { de marzo de } \\
2009\end{array}$ \\
\hline Maureen Ballestero presenta el proyecto 17.694 Ley de Aguas. & $\begin{array}{l}29 \text { de abril de } \\
2010\end{array}$ \\
\hline $\begin{array}{l}\text { ación Arias Sánchez e inicio del gobierno de } \\
\text { anda. }\end{array}$ & $\begin{array}{l}8 \text { de mayo de } \\
2010\end{array}$ \\
\hline $\begin{array}{l}\text { El proyecto } 17.742 \text { Ley de Gestión Integral del Recurso Hídrico } \\
\text { se presenta al Plenario por medio del mecanismo de Iniciativa } \\
\text { Popular. }\end{array}$ & $\begin{array}{l}25 \text { de mayo de } \\
2010\end{array}$ \\
\hline $\begin{array}{l}\text { Al proyecto de Ley del Recurso Hídrico } 14.585 \text { se le vence su } \\
\text { lazo de discusión y es archivado en el expediente } 13.061 \text {. }\end{array}$ & $\begin{array}{l}21 \text { de junio de } \\
2010\end{array}$ \\
\hline $\begin{array}{l}\text { Se presenta el proyecto } 17.793 \text { para incorporar el derecho humano } \\
\text { de acceso al agua a la Constitución (arts.50). }\end{array}$ & $\begin{array}{l}22 \text { de julio de } \\
2010\end{array}$ \\
\hline lonrovecto 16007 rocibe prime & \\
\hline
\end{tabular}




\begin{tabular}{lllll}
\hline & Hecho relevante & \multicolumn{2}{c}{ Fecha } \\
\hline Plenario Legislativo. & \multicolumn{2}{c}{ agosto de 2010 } \\
\hline El proyecto 16.897 ingresa en el orden del día del Plenario & $\begin{array}{l}18 \text { de octubre } \\
\text { de } 2010\end{array}$ \\
Legislativo. & $\begin{array}{l}10 \\
\text { ne presenta al Plenario el proyecto Ley de Asociaciones } \\
\text { Administradoras de Acueductos No17.914. }\end{array}$ & 2010 & de \\
\end{tabular}

Fuente: Elaboración propia a partir de: Expedientes legislativos A-13.061, Tomos 16 al 20 del expediente 14.585, archivado A-13.061. Entrevistas a actores y consultas al sitio oficial de la Asamblea Legislativa, consultado en abril y junio de 2012: http://www.asamblea.go.cr/Centro_de_informacion.

Frente a esta realidad y la renuencia del sistema político para resolver buena parte de las demandas de la sociedad civil, los actores deciden separar sus temas en dos proyectos de ley y buscar la aprobación de sus iniciativas por separado. Esto se traduce en la presentación de los proyectos de ley para incorporar el derecho humano al agua en la Constitución (17.793), el proyecto de ley de Gestión Integral del Recurso Hídrico (17.742) y el proyecto de ley de Asociaciones Administradoras de Acueductos (17.914).

El análisis del conjunto de los cinco ciclos de contienda permite identificar cuatro grandes áreas en disputa, así como a los actores participantes en la contienda por la reforma del marco legal del recurso hídrico en Costa Rica:

1. El manejo del agua en Costa Rica según el enfoque de la gestión integrada de los recursos hídricos. Los principales actores son la comunidad epistémica del agua integrada por Ministerio de Ambiente y Energía (MINAE)Departamento de Aguas, DH, GWP, CEDARENA, FUDEU y otros especialistas de las principales organizaciones civiles y universidades del país así como los partidos Acción Ciudadana (PAC), Frente Amplio (FA), sectores del Partido Liberación Nacional (PLN) y Partido Unidad Social Cristiana (PUSC). Se observa una ruptura interna entre grupo ligado a la ex diputada liberacionista Maureen Ballestero (versión limitada de la GIRH), y por la Alianza Nacional para la Defensa del Agua (ANDA) (versión profunda de la GIRH).

2. La regulación del sector de fuerzas hidráulicas para la generación privada de energía. Los actores relevantes son Asociación Costarricense de Productores de Energía (ACOPE), la comunidad epistémica del agua que veladamente apoyó esta regulación y el MINAE lo hizo abiertamente. La Federación Costarricense para la Conservación de la Naturaleza (FECON) y algunas organizaciones aliadas se opusieron fuertemente a esta iniciativa. El Instituto Costarricense de Electricidad (ICE) mantuvo una posición prudente pues objetaron la apertura del sector energía pero no incidieron directamente para evitarla. El Partido Movimiento Libertario y un sector del Partido Liberación Nacional, ligado al liderazgo del Presidente Óscar Arias Sánchez, apoyaron a este grupo en su pretensión de incluir la regulación de las fuerzas hidráulicas 
en los distintos proyectos del recurso hídrico. Cuando ACOPE optó por regular esa materia en una legislación aparte, contó con el apoyo del PUSC y el PAC además del PML, PLN.

3. Reorganización del sector hídrico con el argumento de que una mejor gobernabilidad resolvería la crisis del recurso en el país. El Instituto Costarricense de Electricidad (ICE) se opuso a perder su régimen de concesión especial y someter su planificación a los dictados del MINAE o los organismos de cuenca. El Instituto Costarricense de Acueductos y Alcantarillados (ICAA) también objetó los cambios en régimen de concesiones, los cobros por conceptos de cánones y la pérdida de su rectoría en materia de agua potable. El sector de los acueductos comunales (ASADAS) también exigió que se les incluyera en la discusión y se reconociera su aporte y funcionamiento en la provisión de servicios de agua potable. El Servicio Nacional de Aguas Subterráneas, Riego y Avenamiento (SENARA) y el Ministerio de Salud se opusieron fuertemente al traslado de sus competencias al MINAE. Estas divisiones internas en el Poder Ejecutivo no pudieron ser resueltas en el periodo de estudio.

4. Equilibrio entre la conservación del recurso y la producción económica del país. Varias cámaras empresariales, lideradas por la Cámara Nacional de Agricultura y Agroindustria (CNAA) y la Unión Nacional de Pequeños y Medianos Productores Agropecuarios (UPANACIONAL) argumentaron que la reforma afectaría las actividades económicas del país. Su principal reclamo estaba relacionado con las normas que regulaban las áreas de protección de nacientes y cuerpos de agua, así como el costo de los cánones que se pretendía implementar. En este reclamo contaron con el apoyo del Ministerio de Agricultura y Ganadería (MAG), el Ministerio de Economía, Industria y Comercio (MEIC) y la Autoridad Reguladora de los Servicios Públicos (ARESEP), así como el apoyo del PLN y el gobierno de Óscar Arias Sánchez.

La figura 2 ilustra los diversos ciclos que siguió la contienda política analizada. Es claro que la espiral se proyecta hacia delante, más allá del año presente (2013), pues la contienda, aún en la actualidad, continúa sin resolverse. 
Figura 2: La espiral de poder en la contienda por la reforma del marco jurídico del recurso hídrico

\section{La espiral del poder en la contienda por la reforma del marco jurídico del recurso hídrico}

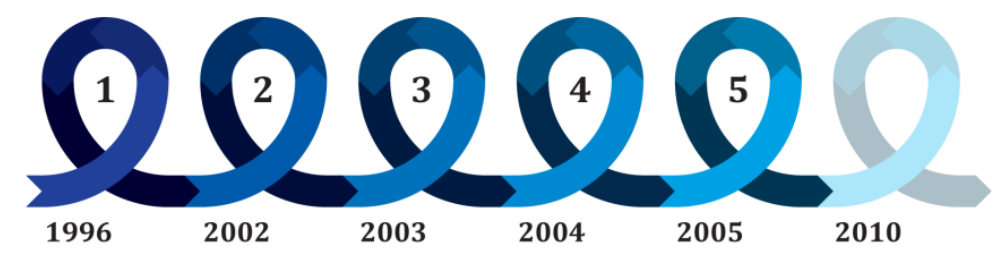

1. Primer ciclo: necesidad de la reforma e integración de los proyectos de ley (1996-2002).

2. Segundo ciclo: proceso de consulta y búsqueda de consensos (2002-2003).

3. Tercer ciclo: entre la división institucional y el disenso social (2003-2004).

4. Cuarto ciclo: aprobación del proyecto de ley en la Comisión de Ambiente (2004-2005).

5. Quinto ciclo: lenta agonía del proyecto de ley 14.585 (2005-2010).

Fuente: Elaboración propia.

Finalmente, interesa volver al supuesto básico del modelo e indagar sobre el ejercicio del poder de los actores interesados en la reforma del marco legal del recurso hídrico en Costa Rica. Para ello, el modelo teórico ha permitido identificar los hechos relevantes ordenados según las fases del ciclo, así como los actores, sus demandas y los principales temas en disputa. La Tabla 4 recupera esa información de los actores y sus demandas y categoriza la incidencia política según el nivel de cumplimiento de las demandas a lo largo del proceso. 
Tabla 4. Balance de la incidencia política de los actores como indicador cualitativo del ejercicio del poder.

\begin{tabular}{|c|c|c|}
\hline \multicolumn{3}{|c|}{ Incidencia política } \\
\hline Actor & Demanda & $\begin{array}{c}\text { Nivel de } \\
\text { cumplimiento }\end{array}$ \\
\hline ACOPE & $\begin{array}{l}\text { Regular el aprovechamiento de fuerzas hidráulicas } \\
\text { para la generación privada de energía }\end{array}$ & $\begin{array}{l}\text { Alto (aprobación de } \\
\text { la ley } 8723 \text { en 2009). }\end{array}$ \\
\hline $\begin{array}{l}\text { Sector } \\
\text { agropecuario } \\
\text { CNAA/ } \\
\text { UPANACIO } \\
\text { NAL }\end{array}$ & $\begin{array}{l}\text { Detener la aprobación del proyecto de ley } 14.585 \\
\text { y cualquier otro cuyas normas relacionadas con } \\
\text { áreas de protección y esquemas de conservación } \\
\text { del recurso hídrico afecte la actividad } \\
\text { agropecuaria. }\end{array}$ & $\begin{array}{l}\text { Alto (ninguna ley en } \\
\text { ese sentido ha sido } \\
\text { aprobada). }\end{array}$ \\
\hline $\begin{array}{l}\text { Cámaras } \\
\text { empresariales } \\
\text { (UCCAEP, } \\
\text { CICR) }\end{array}$ & $\begin{array}{l}\text { Detener la aprobación del proyecto de ley } 14.585 \\
\text { y cualquier otro cuyas normas relacionadas con } \\
\text { áreas de protección y esquemas de conservación } \\
\text { del recurso hídrico afecte la actividad económica. }\end{array}$ & $\begin{array}{l}\text { Alto (ninguna ley en } \\
\text { ese sentido ha sido } \\
\text { aprobada). }\end{array}$ \\
\hline FECON & $\begin{array}{l}\text { Detener cualquier proyecto de ley que permita el } \\
\text { aprovechamiento de fuerzas hidráulicas para la } \\
\text { generación privada de energía. }\end{array}$ & $\begin{array}{l}\text { Bajo (la ley } 8723 \text { fue } \\
\text { aprobada). }\end{array}$ \\
\hline $\begin{array}{l}\text { Acueductos } \\
\text { comunales } \\
\text { (ASADAS) } \\
\end{array}$ & $\begin{array}{l}\text { Reconocer su aporte e incorporar la regulación de } \\
\text { su sector en una nueva ley. }\end{array}$ & $\begin{array}{l}\text { Bajo (ninguna ley en } \\
\text { ese sentido ha sido } \\
\text { aprobada). }\end{array}$ \\
\hline $\begin{array}{l}\text { Comunidad } \\
\text { epistémica del } \\
\text { agua-ANDA }\end{array}$ & $\begin{array}{l}\text { Reformar el marco legal para asegurar una versión } \\
\text { profunda de la gestión integrada del recurso } \\
\text { hídrico. }\end{array}$ & $\begin{array}{l}\text { Bajo (ninguna ley en } \\
\text { ese sentido ha sido } \\
\text { aprobada). }\end{array}$ \\
\hline $\begin{array}{l}\text { Comunidad } \\
\text { epistémica del } \\
\text { agua- } \\
\text { MINAE- } \\
\text { GWP }\end{array}$ & $\begin{array}{l}\text { Reformar el marco legal para asegurar una versión } \\
\text { limitada de la gestión integrada del recurso } \\
\text { hídrico. }\end{array}$ & $\begin{array}{l}\text { Bajo (ninguna ley en } \\
\text { ese sentido ha sido } \\
\text { aprobada). }\end{array}$ \\
\hline $\begin{array}{l}\text { Defensoría de } \\
\text { los Habitantes }\end{array}$ & $\begin{array}{l}\text { Reformar el marco legal para asegurar la } \\
\text { protección de los derechos de los habitantes a } \\
\text { contar con agua potable y saneamiento. }\end{array}$ & $\begin{array}{l}\text { Bajo (ninguna ley en } \\
\text { ese sentido ha sido } \\
\text { aprobada) }\end{array}$ \\
\hline $\begin{array}{l}\text { MINAE- } \\
\text { Dpto. } \\
\text { Aguas }\end{array}$ & $\begin{array}{l}\text { Reformar el marco legal para: 1. asegurar una } \\
\text { versión superficial de la gestión integrada del } \\
\text { recurso hídrico; } 2 \text {. cambiar la estructura } \\
\text { organizativa del sector, incluyendo la rectoría del } \\
\text { MINAE; } \quad 3 \text {. cambiar en competencias } \\
\text { institucionales; 4. liderar la planificación hídrica; } \\
\text { 5. cambiar el régimen de aprovechamiento. }\end{array}$ & $\begin{array}{l}\text { Medio (ninguna ley } \\
\text { en ese sentido ha sido } \\
\text { aprobada; algunos } \\
\text { cambios han ocurrido } \\
\text { vía decreto o } \\
\text { interpretación } \\
\text { jurídica. }\end{array}$ \\
\hline ICE & $\begin{array}{l}\text { Evitar reformas en el marco legal que: } 1 \text {. cambien } \\
\text { el régimen de aprovechamiento; } 2 \text {. le hagan perder } \\
\text { su predominancia en la planificación } \\
\text { hidroeléctrica a favor del MINAE u organismos de } \\
\text { cuenca. }\end{array}$ & $\begin{array}{l}\text { Alto (ninguna ley en } \\
\text { ese sentido ha sido } \\
\text { aprobada) }\end{array}$ \\
\hline
\end{tabular}




\begin{tabular}{|c|c|c|}
\hline \multicolumn{3}{|c|}{ Incidencia política } \\
\hline Actor & Demanda & $\begin{array}{c}\text { Nivel de } \\
\text { cumplimiento }\end{array}$ \\
\hline ICAA & $\begin{array}{l}\text { Evitar reformas en el marco legal que: } 1 \text { cambien } \\
\text { el régimen de aprovechamiento; } 2 \text {. obliguen al } \\
\text { ICAA a incurrir en gastos adicionales por cobro } \\
\text { de cánones; } 3 \text {. la pérdida de su rectoría en materia } \\
\text { de agua potable. }\end{array}$ & $\begin{array}{l}\text { Medio (el ICAA } \\
\text { mantiene su rectoría } \\
\text { pero ha sido obligado } \\
\text { a pagar cánones } \\
\text { establecidos vía } \\
\text { decreto ejecutivo) }\end{array}$ \\
\hline SENARA & $\begin{array}{l}\text { Evitar reformas en el marco legal que les hagan } \\
\text { perder competencias. }\end{array}$ & $\begin{array}{l}\text { Alto (ninguna ley en } \\
\text { ese sentido ha sido } \\
\text { aprobada) }\end{array}$ \\
\hline MINSA & $\begin{array}{l}\text { Evitar reformas en el marco legal que les hagan } \\
\text { perder competencias. }\end{array}$ & $\begin{array}{l}\text { Alto (ninguna ley en } \\
\text { ese sentido ha sido } \\
\text { aprobada) }\end{array}$ \\
\hline MAG & $\begin{array}{l}\text { Detener la aprobación del proyecto de ley } 14.585 \\
\text { y cualquier otro cuyas normas relacionadas con } \\
\text { áreas de protección y esquemas de conservación } \\
\text { afecte la actividad agropecuaria. }\end{array}$ & $\begin{array}{l}\text { Alto (ninguna ley en } \\
\text { ese sentido ha sido } \\
\text { aprobada) }\end{array}$ \\
\hline MEIC & $\begin{array}{l}\text { Detener la aprobación del proyecto de ley } 14.585 \\
\text { y cualquier otro cuyas normas relacionadas con } \\
\text { áreas de protección y esquemas de conservación } \\
\text { afecte la actividad económica. }\end{array}$ & $\begin{array}{l}\text { Alto (ninguna ley en } \\
\text { ese sentido ha sido } \\
\text { aprobada) }\end{array}$ \\
\hline ARESEP & $\begin{array}{l}\text { Detener el uso de mecanismos financieros } \\
\text { (cánones) vía tarifa de servicios públicos para } \\
\text { financiar el uso sostenible del recurso. }\end{array}$ & $\begin{array}{l}\text { Bajo (los cánones } \\
\text { han sido establecidos } \\
\text { vía decreto ejecutivo }\end{array}$ \\
\hline
\end{tabular}

Fuente: Elaboración propia.

\section{Conclusiones}

El análisis de la incidencia política de los actores revela que algunos como la Asociación Costarricense de Productores de Energía (ACOPE), el sector agropecuario (Cámara Nacional de Agricultura y Agroindustria CNAA/ Unión Nacional de Pequeños y Medianos Productores Agropecuarios Costarricenses UPANACIONAL) apoyado por el Ministerio de Agricultura y Ganadería (MAG) y las cámaras empresariales (Unión Costarricense de Cámaras y Asociaciones de la Empresa Privada UCCAEP, Cámara de Industrias de Costa Rica CICR) apoyadas por el MEIC lograron hacer prevalecer sus demandas a lo largo del proceso. Los poderosos vínculos de estos grupos con el Partido Liberación Nacional (PLN), en el poder desde el 2006 hasta el 2010, así como con la oposición, ya sea el Partido Movimiento Libertario y ciertos sectores del Partido Unidad Social Cristiana (PUSC) y el Partido Acción Ciudadana (PAC), explican la efectividad de la intermediación e incidencia política de estas cámaras gremiales. El Instituto Costarricense de Electricidad (ICE), Servicio Nacional de Aguas, Riego y 
Avenamiento (SENARA) y el Ministerio de Salud (MINSA) también tienen un alto nivel de incidencia política, pero en este caso sus vínculos partidarios y políticos se encuentran en lo interno del Poder Ejecutivo y altos puestos de esas instituciones.

El Ministerio de Ambiente y Energía (MINAE) ha tenido una incidencia política media, pues si bien no ha conseguido imponer sus demandas por la vía de la reforma legal, sí ha logrado cambios en el marco institucional por medio de decretos ejecutivos, fallos de la Sala Constitucional e interpretaciones jurídicas. El Instituto Costarricense de Acueductos y Alcantarillados (ICAA) ha evitado cambios legales que le hagan perder su rectoría en materia de agua potable, pero ha sido obligado a someterse a los instrumentos financieros dispuestos por el MINAE.

Esos instrumentos financieros no han sido implementados según lo demandado por la Autoridad Reguladora de los Servicios Públicos (ARESEP), por lo que la incidencia política de esta entidad se califica como baja. De igual forma, la Federación Costarricense para la Conservación de la Naturaleza (FECON) tuvo una baja incidencia política pues no consiguió impedir la aprobación de la ley que regula el aprovechamiento de fuerzas hidráulicas para la generación privada de energía. En estos casos, los vínculos partidarios se han dado con aquellos partidos de menor caudal electoral como el Frente Amplio o con sectores minoritarios dentro del PAC.

Los acueductos comunales tampoco lograron que se legislara en su favor por lo que se les cataloga como baja incidencia. Tampoco tuvo éxito la comunidad epistémica del agua, ni en su versión profunda (ANDA), ni en su versión limitada (MINAE-GWP), por lo que su incidencia es baja. Asimismo, la Defensoría de los Habitantes tampoco ha logrado reformar el marco legal para proteger el derecho de los habitantes a acceder al agua potable y el saneamiento.

A pesar del poco éxito de estos últimos actores, no puede afirmarse que su incidencia política haya sido nula, pues es posible identificar un impacto en los marcos cognitivos sobre el agua en el país. Cada vez es más evidente en los medios de comunicación y la opinión pública el interés de la ciudadanía respecto al uso adecuado del recurso. El discurso mayoritario, que por muchos años prevaleció en el país y que afirmaba que el agua era infinita, se vuelve minoritario y se acompaña, cada vez más, de un convencimiento mayor sobre la importancia de cambiar el rumbo de la gestión del agua.

La tendencia histórica que asocia cambios societales profundos con cambios en el marco legal del recurso hídrico se rompe parcialmente en este periodo. Para estar acorde con los tiempos, la reforma tendría que haber ocurrido y su orientación tendría que haber sido más aperturista y con mayor participación del mercado. Esto ocurrió en el caso de la regulación del aprovechamiento de las fuerzas hidráulicas para generación privada y la aplicación de instrumentos de mercado -cánones vía decreto- para la protección del recurso. Sin embargo, la división de la comunidad epistémica del agua en dos bandos expresa la contradicción de los sectores que proponían la reforma para lograr una gestión integrada del recurso. De hecho, ninguno de ellos ha tenido suficiente poder como para impulsar una reforma, ni superficial ni parcial. Cabe destacar que en ningún caso se ha propuesto una 
reforma para privatizar el agua o su gestión. Esto demuestra la existencia de un discurso, aún mayoritario en el país, que entiende la importancia de que la gestión del agua atienda a criterios de solidaridad, servicio público y derechos humanos. Sin embargo, dicho convencimiento no alcanza tampoco para lograr una reforma que profundice las normas en ese sentido. Esto es así porque los sectores más poderosos, empresarios agropecuarios e industriales, han objetado cualquier reforma que perjudique sus intereses.

La aplicación del modelo teórico a este caso de estudio ha permitido una mayor claridad en la clasificación de la información y ha contribuido a manejar la enorme complejidad de temas, actores y demandas presentes. El modelo teórico ha servido, además, para estudiar las relaciones de poder en un contexto específico y, como tal, ha logrado comprobar empíricamente la forma y consecuencias del ejercicio del poder. La tarea pendiente es estudiar otros procesos, otras contiendas, otras espirales de poder.

\section{Bibliografía}

Abarca Rodríguez, A., Alpízar Rodríguez, F., Rojas Benavides, C., Sibaja Quesada, G., (2012), Técnicas cualitativas de investigación, Editorial de la Universidad de Costa Rica, Costa Rica.

Abarca, A. (2002), "Las políticas públicas como perspectiva de análisis.” Revista de Ciencias Sociales, N97, Vol. (III), 2002, Universidad de Costa Rica.

Alpízar Rodríguez, F. (2013), “¿Democracia ecológica? Las instituciones, la participación política y las contiendas por el agua en Costa Rica (1821-2010).” Tesis Doctoral dirigida por Dra. Paloma Román Marugán, Facultad de Ciencias Políticas y Sociología, Universidad Complutense de Madrid, Madrid.

Alpízar, F. (2007), La influencia del poder en la política comercial de Costa Rica: el caso de los lecheros en el TLC con México, Editorial de la Universidad de Costa Rica, Costa Rica.

Blanco Lobo, M (2006), Incidencia política como estrategia de comunicación social para institucionalizar la equidad de género. Tesis de grado. Master Scientiae en Comunicación. Sistema de Estudios de Posgrado. Universidad de Costa Rica, Costa Rica.

Bourdieu, P. (1985). ¿Qué significa hablar? Economía de los intercambios lingüísticos, Editorial Akal, Madrid.

Castells, M. (2009), Comunicación y poder, Alianza Editorial, Madrid.

CIRD (2001), El cabildeo: una estrategia para incidir en las políticas públicas, Centro de Información y Recursos para el Desarrollo, Paraguay

De la Ossa, A. (2002), “Incidencia en Centroamérica ¿autoengaño o realidad?” En:

Revista Pensamiento Propio. Nueva Época, año 7. N¹5. Enero-julio, 2002, pp.47-72.

Foucault, M. (1981), Un diálogo sobre el poder y otras conversaciones, Alianza Editores, Madrid. 
Grupo Técnico del Agua (2004), Hacia una nueva ley del Agua. Memoria de un proceso de construcción participativa.Grupo Técnico del Agua, San José

Haas, P. (1992), "Introduction: epistemic communities and international policy coordination”, International Organization, Vol.46, $\mathrm{N}^{\circ} 1$ Knowledge, Power and International Policy Coordination. (Winter, 1992), pp. 1-35.

Hernández Naranjo, G. (2009), "Partidos políticos y calidad de la democracia: participación y representación en el contexto de cambio del bipartidismo al pluralismo moderado en Costa Rica." Ponencia sometida al $21^{\circ}$ Congreso Mundial de Ciencia Política IPSA. Chile. Inédito.

Jessop, B. (2008), State Power, Polity Press, UK.

Keohane, R., Nye, J. (1988), Poder e interdependencia, GEL, Buenos Aires.

Lukes, S. (2007). El poder. Un enfoque radical, Siglo XXI Editores, Madrid.

Mann, M. (1984), "The autonomous power of the State: its origins, mechanisms and results.” Archives Eropeenes de sociologie, Vol.25 1984, pp.185-213.

Montero, J. R., Gunther, R., Linz, J. (2007). Partidos políticos. Viejos conceptos y nuevo retos, Editorial Trotta, Madrid.

Powell, B. (2007), "Aggregating and representing political preferences.” Boix, C., Stokes, S. (eds.), The Oxford Handbook of Comparative Politics, Oxford University Press, Oxford-New York

Prats, J. (2004), "De la burocracia al management y del management a la gobernanza.” Instituciones y Desarrollo. Num.3.

Rosales Valladares, R. (2008). "La institucionalización, democratización y transparencia internas de los partidos políticos en Costa Rica.” Tesis para optar por el título de Doctor en Ciencias Sociales. Costa Rica: Facultad Latinoamericana de Ciencias Sociales.

Tilly, Ch., Tarrow, S., (2007), Contentious politics, Paradigm Publishers, USA.

Vargas Cullel, J. (2012), "Advancing the study of Stateness in Central America: Methodology and some ilustrative findings." Revista de Ciencia Política, Volumen 32/ $\mathrm{N}^{0} 3 / 2012 / 703-721$, Chile.

WOLA (2005). Manual para la facilitación de procesos de incidencia política. Oficina en Washington para Asuntos de América Latina WOLA-Centro para el Desarrollo de Actividades de Población CEDPA, Washington. 